\title{
Interactions between amphibians' symbiotic bacteria cause the production of emergent anti-fungal metabolites
}

\author{
Andrew H. Loudon ${ }^{1}$, Jessica A. Holland ${ }^{1}$, Thomas P. Umile ${ }^{2}$, Elizabeth A. Burzynski ${ }^{2}$, \\ Kevin P. C. Minbiole ${ }^{2}$ and Reid N. Harris ${ }^{1}$
}

1 Department of Biology, James Madison University, Harrisonburg, VA, USA

2 Department of Chemistry, Villanova University, Villanova, PA, USA

\section{Edited by:}

Ana E. Escalante, Universidad

Nacional Autónoma de México,

Mexico

Reviewed by:

Sebastian Fraune,

Christian-Albrechts Universität Kiel,

Germany

Peter David Newell, Cornell

University, USA

*Correspondence:

Andrew H. Loudon, Department of Biology, James Madison University, 951 Carrier Drive, MSC 7801 Harrisonburg, VA 22807, USA e-mail: loudonah@jmu.edu
Amphibians possess beneficial skin bacteria that protect against the disease chytridiomycosis by producing secondary metabolites that inhibit the pathogen Batrachochytrium dendrobatidis $(B d)$. Metabolite production may be a mechanism of competition between bacterial species that results in host protection as a by-product. We expect that some co-cultures of bacterial species or strains will result in greater $B d$ inhibition than mono-cultures. To test this, we cultured four bacterial isolates (Bacillus sp., Janthinobacterium sp., Pseudomonas sp. and Chitinophaga arvensicola) from red-backed salamanders (Plethodon cinereus) and cultured isolates both alone and together to collect their cell-free supernatants (CFS). We challenged Bd with CFSs from four bacterial species in varying combinations. This resulted in three experimental treatments: (1) CFSs of single isolates; (2) combined CFSs of two isolates; and (3) CFSs from co-cultures. Pair-wise combinations of four bacterial isolates CFSs were assayed against $B d$ and revealed additive $B d$ inhibition in $42.2 \%$ of trials, synergistic inhibition in $42.2 \%$ and no effect in $16.6 \%$ of trials. When bacteria isolates were grown in co-cultures, complete $B d$ inhibition was generally observed, and synergistic inhibition occurred in four out of six trials. A metabolite profile of the most potent co-culture, Bacillus sp. and Chitinophaga arvensicola, was determined with LC-MS and compared with the profiles of each isolate in mono-culture. Emergent metabolites appearing in the co-culture were inhibitory to $B d$, and the most potent inhibitor was identified as tryptophol. Thus mono-cultures of bacteria cultured from red-backed salamanders interacted synergistically and additively to inhibit $B d$, and such bacteria produced emergent metabolites when cultured together, with even greater pathogen inhibition. Knowledge of how bacterial species interact to inhibit $B d$ can be used to select probiotics to provide amphibians with protection against $B d$.

Keywords: Batrachochytrium dendrobatidis, emergent metabolites, amphibians, symbiotic bacteria, anti-fungal metabolites, host-associated microbial communities, interspecific competition, synergy

\section{INTRODUCTION}

Amphibians are experiencing global population declines and are the most threatened vertebrate class (Stuart et al., 2004; Hoffmann et al., 2010). Indeed, 41 percent of amphibian species are threatened. Among the many factors that contribute to amphibian declines, the fungal disease chytridiomycosis, caused by the pathogen Batrachochytrium dendrobatidis $(B d)$, is the largest disease threat to the biodiversity of any vertebrate group (Wake and Vredenburg, 2008; Hoffmann et al., 2010). Alarmingly, disease-induced declines occur in protected, pristine environments, such as national parks, where up to 92.5 percent of critically endangered amphibian species are affected by $B d$ (Kilpatrick et al., 2010).

Amphibians have several defenses against $B d$, including symbiotic bacteria living on their skins (Harris et al., 2006). Numerous anti-fungal bacterial species have been cultured from amphibians (Lauer et al., 2007; Woodhams et al., 2007), and their presence is associated with disease resistance (Becker and Harris, 2010).
Additionally, using culture-independent techniques, diverse hostspecific bacterial communities have been observed on amphibians (McKenzie et al., 2011; Kueneman et al., 2013; Loudon et al., 2013; Walke et al., 2014). One promising mitigation strategy against $B d$ is to augment the bacterial communities on amphibians' skin to increase disease resistance (Harris et al., 2009b; Bletz et al., 2013). This approach of using bacterial probiotics has been successful in laboratory experiments and one field trial (Becker et al., 2009; Vredenburg et al., 2011).

Amphibian-associated bacteria can inhibit $B d$ by producing anti-fungal metabolites (Brucker et al., 2008a,b). Several anti- $B d$ metabolites are produced from amphibian skin bacteria, such as violacein and indole-3-carboxaldehyde (I3C) from Janthinobacterium lividum and 2,4-diacetylphloroglucinol is produced Lysobacter gummosus (Brucker et al., 2008a,b). Additionally, evidence from free-living salamanders in nature suggests that the concentration of bacterially produced metabolites on their skins can be high enough to kill pathogenic fungi, 
such as $B d$ (Brucker et al., 2008b). Moreover, a positive correlation was found between the abundance of the amphibian symbiont J. lividum and violacein on red-backed salamanders; salamanders with more J. lividum and violacein had less morbidity due to chytridiomycosis (Becker et al., 2009).

A recent model on the assembly of beneficial microbiomes suggests that the microbiota's defensive function is a by-product of interspecific competition among microbial species (Scheuring and $\mathrm{Yu}, 2012$ ). If microbial population densities reach the point where competition occurs and enough energy is available, defensive chemical production can be triggered that may defend the host. Without conditions of interspecific competition (pure culture), a weaker defensive function may occur. For example, bacteria cultured separately have been found to not produce antifungal compounds, but do produce anti-fungal compounds when cultured together (De Boer et al., 2007). In this study, we tested the hypothesis that conditions that favor interspecific competition will result in greater inhibition of $B d$ than under conditions of no interspecific competition. We hypothesized that greater inhibition of $B d$ would be caused by the production of emergent metabolites (i.e., metabolites produced in co-culture but not produced in mono-culture) that are only found with interspecific competition.

\section{MATERIALS AND METHODS COLLECTION AND IDENTIFICATION OF ANTI-BD BACTERIAL ISOLATES}

The bacterial isolates in this study were cultured from red-backed salamanders (Plethodon cinereus) that were sampled from George Washington National Forest in October, 2011. Four bacterial isolates were chosen because they inhibit $B d$ in mono-culture. The bacterial isolates were maintained in culture in $16 \times 125 \mathrm{~mm}$ test tubes with approximately $2 \mathrm{~mL} 1 \%$ tryptone broth and incubated in a shaking incubator at $25^{\circ} \mathrm{C}$. Using traditional PCR, a portion of the $16 \mathrm{~S}$ rRNA gene was amplified using the universal $8 \mathrm{~F}$ and $1492 \mathrm{R}$ primers. Reaction conditions are given in Lauer et al. (2007). The DNA was sequenced (EuroFins MWG Operon; Huntsville, Alabama), and Genious (Biomatters Limited; Auckland, New Zealand) was used to assemble the forward and reverse sequences. The GenBank database was used to identify each bacterial isolate.

\section{COLLECTION OF ANTI-BD BACTERIAL SPECIES' CELL-FREE SUPERNATANTS}

To test bacterial isolates for $B d$ inhibition, we used a 96-well plate assay from Bell et al. (2013). Each bacterial species was recultured into a sterile $16 \times 125 \mathrm{~mm}$ test tube containing $2 \mathrm{~mL}$ of $1 \%$ tryptone broth for 3 days and placed in an incubator at $26^{\circ} \mathrm{C}$ prior to the assay. Therefore, each culture had the same nutrient and environmental conditions for the same amount of time as a way to standardize growth conditions. After 3 days, cultures were noticeably turbid. To acquire cell-free supernatants (CFSs), each bacterial isolate was placed in a centrifuge tube and then homogenized with a vortexer. The bacterial isolates were then centrifuged for $5 \mathrm{~min}$ at $10,000 \mathrm{rpm}$. After centrifugation, the supernatants were filtered using a $0.22 \mu \mathrm{m}$ filter (Millipore ${ }^{\mathrm{TM}}$ nitrocellulose membrane), and these solutions contained bacterial metabolites as well as other cell products. This starting solution was designated as the "high" concentration. "Medium" and "low" concentrations were 10- and 100-fold dilutions, respectively, of the "high" concentration, using $1 \mathrm{X}$ phosphate-buffered saline solution.

\section{DETERMINATION OF THE INDIVIDUAL AND COMBINED EFFECTS OF ANTI-BD BACTERIAL ISOLATES ON BD INHIBITION}

A concentration series of each isolate's CFS, alone and in combination, was used in pairwise combinations with $B d$ in a 96 well plate assay. All wells contained $50 \mu \mathrm{L}$ of $B d$ zoospores at $2 \times$ $10^{6}$ zoospores/mL in $1 \%$ tryptone broth $\left(10^{5}\right.$ zoospores/well $)$. $B d$ zoospores were collected using the protocol of Harris et al. (2009b). To test the inhibitory effects of a single isolate, we added $25 \mu \mathrm{L}$ CFS and $25 \mu \mathrm{L}$ water to each well. To test the potential additive effects of two bacterial isolates grown separately, we added $25 \mu \mathrm{L}$ of each isolate's CFS to each well. We called the latter treatment "separate then combined." Each of these treatments was replicated five times. Positive control wells received $50 \mu \mathrm{L}$ of sterile water without any CFSs. Negative control wells received $50 \mu \mathrm{L}$ of heat killed $B d$ zoospores $\left(2 \times 10^{6}\right.$ zoospores $\left./ \mathrm{mL}\right)$, which were killed by placing them at $60^{\circ} \mathrm{C}$ for $20 \mathrm{~min}$. Each of these treatments was replicated five times. Optical density (OD) readings at $490 \mathrm{~nm}$ were obtained at day 0 and day 5 . The change in OD between days 0 and 5 indicated the amount of $B d$ growth in each well, with greater differences reflecting more $B d$ growth.

\section{DETERMINATION OF THE EFFECTS OF INTERSPECIFIC COMPETITION ON BD INHIBITION}

To assess the effects of interspecific bacterial competition on $B d$ inhibition, bacterial species were cultured in paired combinations for 3 days prior to assays with $B d$. For these co-culture treatments, $5 \mu \mathrm{L}$ of the original culture of each bacterial species was placed into a test tube containing $2 \mathrm{~mL}$ of $1 \%$ tryptone broth. Monocultures and additional "separate then combined" assays were done using the procedures stated above as comparisons. Bacterial culturing conditions were the same as the previous assay. The co-culture wells contained $50 \mu \mathrm{L}$ of the CFS from paired combinations of bacterial species, and each treatment was replicated five times.

\section{DETECTION AND ISOLATION OF EMERGENT METABOLITES}

CFC's of monocultures and co-cultures of all isolates were extracted with ethyl acetate according to the method of Brucker et al. (2008a). The Bacillus sp. and Chitinophaga arvensicola combination was focused on since they resulted in the greatest $B d$ inhibition in co-culture. The resulting crude extracts were evaporated to dryness in vacuo, reconstituted in $0.75 \mathrm{~mL}$ methanol, and analyzed by reversed-phase, high performance liquid chromatography (HPLC, $25 \mu \mathrm{L}$ injection) using a Shimadzu LC-20 liquid chromatograph equipped with an ACE C18 column $(3 \mu \mathrm{m}$, $150 \times 4.6 \mathrm{~mm}$ ) according to the method of Umile et al. (2014). Comparison of the chromatograms showed the appearance of at least six metabolites in the co-culture that were not present in either monoculture (Figure 3). Metabolite peaks that were observed in co-cultures, but not present in either of the two individual cultures, were identified as emergent metabolites. These metabolites were isolated by semi-preparative HPLC [ACE C18 
column $(5 \mu \mathrm{m}, 250 \times 10 \mathrm{~mm})]$ and assayed for bioactivity toward $B d$ (see below). To test this, each fraction was suspended in $5 \%$ DMSO solution, to facilitate the dissolution of metabolites. $10 \mu \mathrm{L}$ of each metabolite solution was added to $40 \mu \mathrm{L}$ of a $B d$ zoospore solution resulting in a final concentration of $10^{6}$ zoospores $/ \mathrm{mL}$. The final concentration of each metabolite was $\approx 2 \mu \mathrm{g} / \mathrm{mL}$. In addition, tests were performed without the use of DMSO as a co-solvent with low concentrations of each metabolite that were not quantified. These tests suggested that the compound eluting at $13.48 \mathrm{~min}$ ("Compound 3") was the most inhibitory (Figure 4).

\section{CHARACTERIZATION AND IDENTIFICATION OF "COMPOUND 3"}

An inhibitory compound eluting at $13.48 \mathrm{~min}$ ("Compound 3") was isolated using the semi-preparative HPLC described above and analyzed by ${ }^{1} \mathrm{H}$ NMR and liquid chromatography-mass spectrometry (LC-MS). ${ }^{1} \mathrm{H}$ NMR spectra were measured with a $300 \mathrm{MHz}$ Varian spectrophotometer. UV-Vis measurements utilized a Shimadzu SPD-M20A diode array detector, and mass spectrometry used an Applied Biosystems SCIEX API 2000 triple quadrupole mass spectrometer operating in positive electrospray ionization mode.

\section{BIOASSAY WITH METABOLITE AND BD}

The $\mathrm{IC}_{50}$ for the emergent metabolite, tryptophol, against $B d$ strain JEL310 was determined using a 96 well plate method assay previously developed by Brucker et al. (2008a).

\section{STATISTICAL ANALYSES}

Analyses of variance (ANOVA) were used to test for the main effects of species' CFS on $B d$ inhibition. A significant interaction effect indicated that either synergy or antagonism between species' CFS was present. Dunnett's test was used for a posteriori tests to compare treatments to controls, and Tukey's test was used to compare each treatment to each other to identify an interaction effect (synergy or antagonism) when one was present.

\section{RESULTS}

\section{BACTERIAL IDENTIFICATION}

Isolates were determined to be a Bacillus sp., Janithobacterium sp., Pseudomonas sp., and Chitinophaga arvensicola (Table 1; sequences Genbank accession \#'s KJ923801, KJ923802, KJ923803 and KJ923804 respectively). The genera of all four isolates were represented within the Illumina dataset presented in Loudon et al. (2013). In addition, OTUs within the family Pseudomonadaceae were within the core bacterial community and Janthinobacterium lividum was highly prevalent on red-backed salamanders.

\section{"SEPARATE THEN COMBINED" ASSAYS}

To determine the effect of combined bacterial isolates on $B d$ inhibition we used a "separate then combined" assay where isolates were first grown in mono-culture, and then combined together to challenge $B d$. The six combinations of the four bacterial species' CFSs demonstrated several effects on the growth of $B d$ in comparison to the positive $B d$ control (Supplementary Table 1). The "separate then combined" results for Pseudomonas sp. and Chitinophaga arvensicola were not included due to failure of the positive controls; this resulted in 45 "separate then combined"
Table 1 | Identities of anti-Bd bacterial isolates used in inhibition assays.

\begin{tabular}{lccc}
\hline Identity & \% match & E-value & Accession number \\
\hline Bacillus sp.* $^{*}$ & 100 & 0 & KJ923801 \\
Pseudomonas sp.* $^{*}$ Janthinobacterium sp. $^{*}$ & 100 & 0 & KJ923802 \\
Chitinophaga arvensicola $^{*}$ & 99 & 0 & KJ923803 \\
\hline
\end{tabular}

*Isolates were only identified to the Genus level.

combinations. Of the 45 combinations assayed, some produced an additive effect when assayed with $B d$, some synergistically inhibited the growth of $B d$ in comparison to the positive control, and others had no effect on $B d$ growth.

Of the total of 45 isolate-CFS concentration combinations, 19 of these exhibited an additive relationship when assayed against $B d$. These pairs showed an effect on $B d$ growth equal to the sum of the effects of the CFSs of each species. One example of an additive relationship was between the medium concentration of Bacillus sp. CFS and the low concentration of Janthinobacterium sp. CFS (Figure 1A). There was a tendency of high concentration combination of both isolates to have additive effects as well.

There were 19 isolate-CFS concentration combinations that inhibited $B d$ synergistically. These combinations inhibited $B d$ with a greater total effect than the additive relationship. Concentration combinations were identified as synergistic if their statistical interactions were significant. For example, the combinations of the medium concentration of Bacillus sp. CFS with the medium concentration of Pseudomonas sp. resulted in synergy (Figure 1B).

\section{CO-CULTURE ASSAYS}

The CFSs from co-cultured bacterial isolates showed greater inhibition of $B d$ than the "separate then combined" CFSs in some cases. Out of the six co-culture combinations, four resulted in synergistic inhibition of $B d$, one resulted in additive inhibition of $B d$, and one resulted in synergistic facilitation of $B d$ (Supplementary Table 2). The co-cultured combinations of Bacillus sp./Janthinobacterium sp., Bacillus sp./Pseudomonas sp., Bacillus sp./C. arvensicola (Figure 2) and Janthinobacterium sp./C. synergistically inhibited $B d$. The co-culture combination of Pseudomonas sp./C. arvensicola additively inhibited Bd. Lastly, the combination Pseudomonas sp./Janthinobacterium sp. synergistically facilitated $B d$.

The "separate then combined" assays that were repeated for a comparison with the co-culture assays sometimes differed from initial "separate then combined" trials. For the Bacillus sp./ Pseudomonas sp. combination, the "separate then combined" treatments from the two different trials were significantly different between trials. These comparisons were performed after standardizing the OD values by the positive controls from the two different assays.

\section{EMERGENT METABOLITES}

The co-culture between Bacillus sp. and Chitinophaga arvensicola produced seven isolated emergent metabolites (Figure 3 ) that 


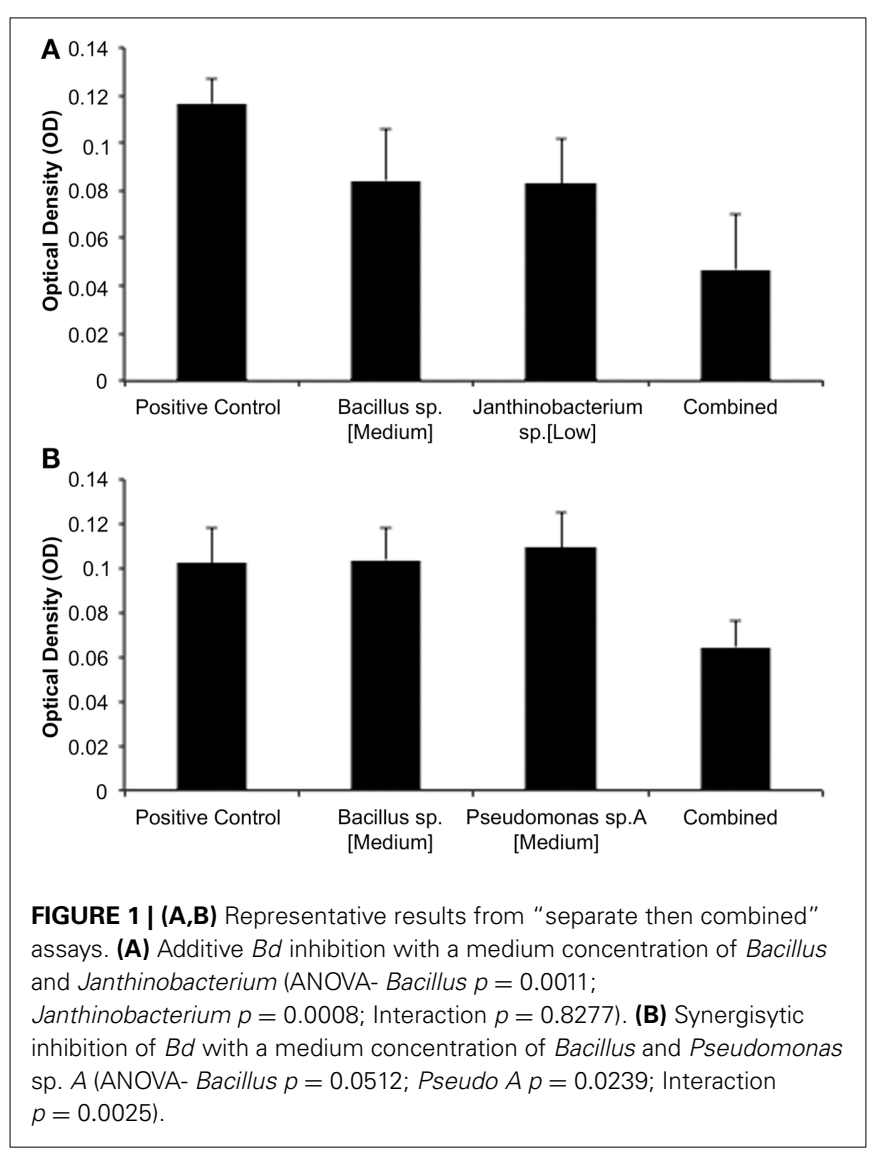

were all inhibitory to $B d$ growth at an approximate concentration of $2 \mu \mathrm{g} / \mathrm{mL}$. An additional test that did not use DMSO as a cosolvent and using low unquantified metabolite concentrations revealed that three compounds were inhibitory, with Compound 3 being the most inhibitory (Figure 4 ).

Compound 3 was identified as tryptophol by multiple chemical methods (UV-Vis spectroscopy, mass spectrometry, and ${ }^{1} \mathrm{H}$ NMR spectroscopy). Accordingly, isolated Compound 3 and an authentic tryptophol standard co-elute $(13.48 \mathrm{~min})$ and share a characteristic indole chromophore with peaks at 280 and $289 \mathrm{~nm}$ (Figure 5). Additionally, ESI-MS of a tryptophol standard and Compound 3 both show a characteristic $144 \mathrm{~m} / \mathrm{z}$ peak corresponding to an $\left[\mathrm{M}-\mathrm{H}_{2} \mathrm{O}\right]^{+}$ion; finally, the ${ }^{1} \mathrm{H}$ NMR spectrum of isolated Compound 3 matches that of authentic tryptophol. Authentic tryptophol inhibited $B d$ (Figure 6) and displayed an $\mathrm{IC}_{50}$ of $\sim 100 \mathrm{ppm}(\sim 600 \mu \mathrm{M})$.

The metabolite profiles for Pseudomonas sp. and Janthinobacterium sp. were also examined since this combination resulted in $B d$ facilitation. Janthinobacterium sp. had three metabolites that were present in the mono-culture that were not present in the co-culture; therefore, $B d$ was challenged with a different suite of metabolites than when challenged with the mono-cultures.

\section{DISCUSSION}

Combinations of bacterial isolate's CFSs exhibited several different relationships in the inhibition of $B d$, demonstrating that the isolates, and the concentrations of an isolate's CFSs, are important factors in $B d$ inhibition. In some cases, the inhibition caused by two isolates CFSs had an additive effect on $B d$ growth inhibition. Other combinations inhibited $B d$ growth synergistically. Some combinations did not demonstrate any effect on $B d$ growth.

The in vitro model of combining CFSs can represent spatially separated isolates on amphibian skin whose secreted metabolites combine in the interstices between them. The different relationships among the pairwise combinations between the four isolates in high, medium and low concentrations demonstrate the variability of bacterial interactions that are likely found in nature. It is unknown how isolates are distributed on amphibian skins, much less their relative population densities, but it is likely to be variable even on a single host individual. In an additive relationship, the metabolites of both bacterial isolates are contributing equally to the inhibition of $B d$ growth. Synergistic relationships may be the result of anti-fungals with different modes of action (Ghannoum and Rice, 1999). As a hypothetical example, in our system a metabolite from the first bacterial isolate may puncture the cell wall of $B d$, whereas the metabolites from the second bacterial isolate may inhibit translation.

Emergent metabolites were identified that were present in bacterial co-cultures, but not present in bacterial mono-cultures. CFSs from co-cultures were often more inhibitory of $B d$ than combining CFSs from mono-cultures. Co-culturing is a model of isolates on the skins that are in the same or close spatial location and are competing with each other by starting to produce additional inhibitory metabolites, and these new metabolites are one reason for greater inhibition of $B d$. Furthermore, emergent metabolites may be synergistically interacting with the metabolites produced in mono-culture and other emergent metabolites to enhance their collective killing power. We determined that these emergent metabolites are anti- $B d$ and determined the identity and $\mathrm{IC}_{50}$ of the most inhibitory metabolite, tryptophol. Although it is inhibitory, it is much less potent than previously identified anti- $B d$ metabolites such as violacein (Brucker et al., 2008b). Tryptophol has been found to be produced by fungi such as Ceratocystis adipose (Guzmán-López et al., 2007), Candida albicans (Lingappa et al., 1969), Pythium ultimum (Rey et al., 2001), Drechslera nodulosum (Sugawara and Strobel, 1987), and Zygosaccharomyces priorianus (Rosazza et al., 1973). The mechanism that tryptophol uses to inhibit $B d$ is unknown. We hypothesize that these emergent metabolites are interacting to cause the greater $B d$ inhibition found in the co-culture assays. The strong inhibition of $B d$ caused by the co-culture CFSs supports the hypothesis that interspecific competition led to greater $B d$ inhibition than intraspecific competition alone (De Boer et al., 2007; Scheuring and Yu, 2012). Furthermore, it suggests that competing microbial species in amphibian skins would enhance disease protection.

One case of facilitation occurred in co-culture between Pseudomonas sp. and Janthinobacterium sp. This result is intriguing since when the bacteria were grown separately and then combined, they did not result in facilitation. Previous work 


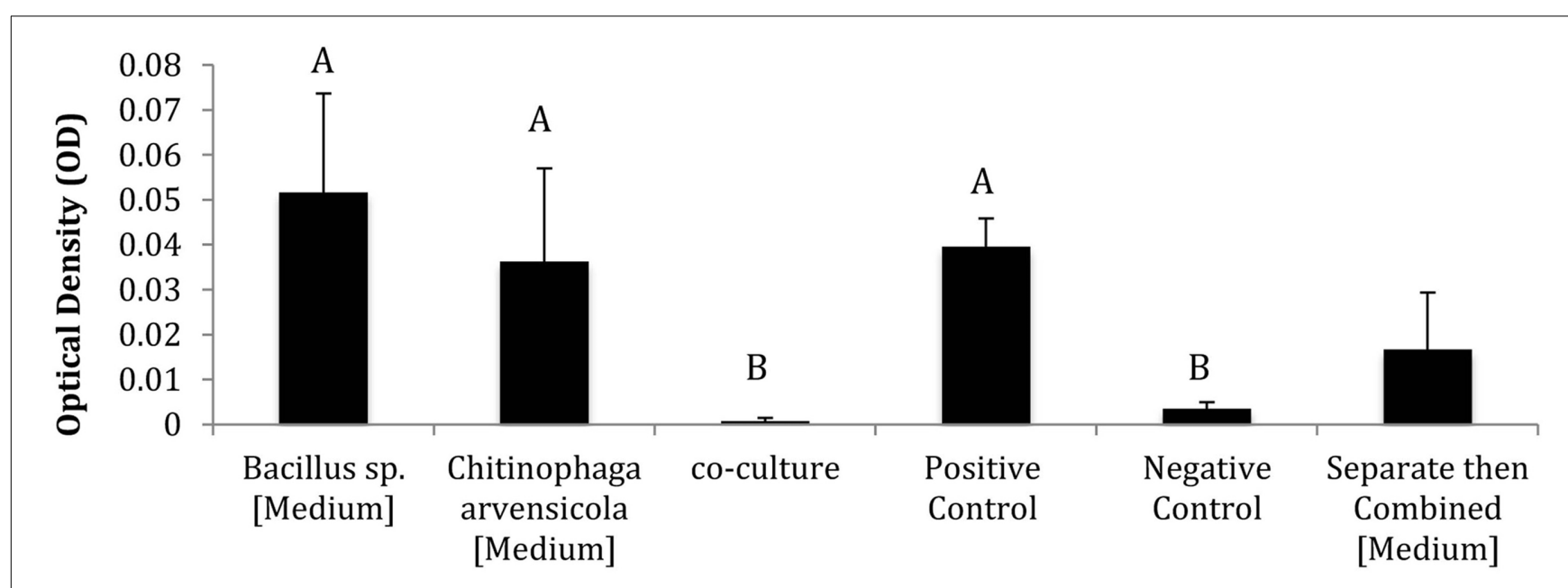

FIGURE 2 | Representative results of co-culture vs. mono-culture assay using Bacillus sp. and Chitinophaga arvensicola (Different letters indicate that treatments are significantly different at $p<0.05$ level

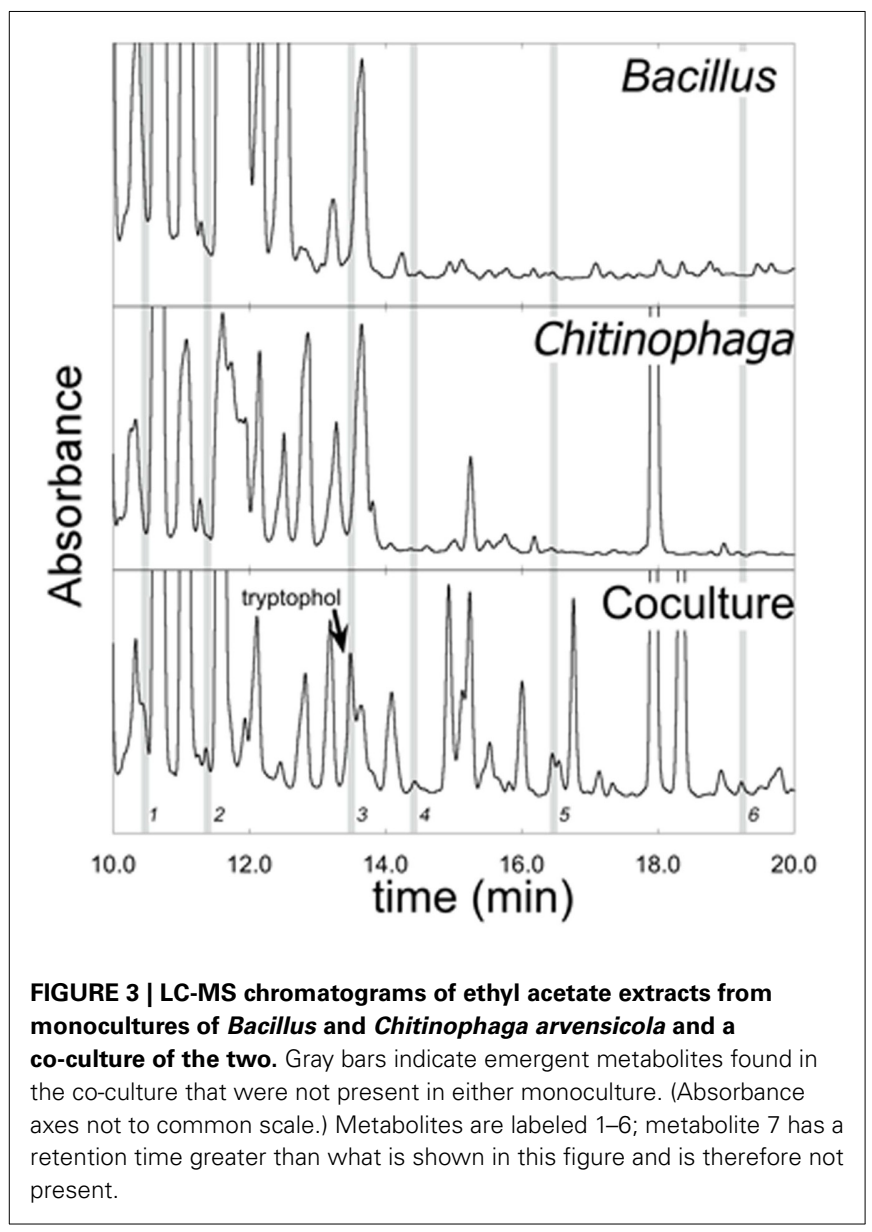

using a similar protocol to determine bacteria's effect on $B d$ found facilitation of $B d$ growth by some isolate's CFSs (Bell et al., 2013). Pseudomonas can produce a number of antifungal metabolites and Janthinobacterium has been widely studied as an using Tukey's test). The "separate then combined" results for this isolate combination are also included as a comparison.

anti- $B d$ bacterium, so facilitation of $B d$ was surprising. In our study, the co-culture lacked metabolites that were found in the Janthinobacterium mono-culture. This shift in metabolites may have led to the facilitation of $B d$.

When the "separate then combined" assays were repeated, the results differed to some extent between trials. In particular, synergy between certain pairs of isolates in the first experiment was not always found in the second experiment. A possible reason for this is that isolates were under somewhat different densities in culture due to stochastic variation. As a result, isolates produced different concentrations of metabolites that then interacted differently when combined. An additional reason may be the age of the media used or the use of different batches of media that had slight chemical differences. Also, it is possible that mutation in laboratory stocks led to different outcomes in the assays. However, all of the results demonstrate that additive and synergistic interactions occur among amphibians' skin bacteria, which depend on a variety of factors, including bacterial species identify and chemical concentration.

The inhibitory interactions between different bacterial species are not the only chemical interactions that inhibit $B d$ within the amphibian skin system. Myers et al. (2012) found synergistic interactions between the antimicrobial peptides (AMPs) from the skin of the frog, Rana muscosa, and the known anti-Bd metabolite 2,4-diacetylphloroglucinol (2,4-DAPG), which is produced by the bacterium Pseudomonas fluorescens. It is likely that AMPs interact with other bacterially-produced metabolites to inhibit $B d$, especially since we found that bacteria produce a high richness of metabolites. Bacteria also produce AMPs that may inhibit $B d$, although we focused on smaller metabolites that are produced by bacteria.

Our results support the hypothesis that competition between different bacterial species causes greater $B d$ inhibition. Bacterial species compete through the production of defensive compounds, which leads to their competitive dominance. Therefore, the host obtains a defensive benefit as a by-product of microbial 


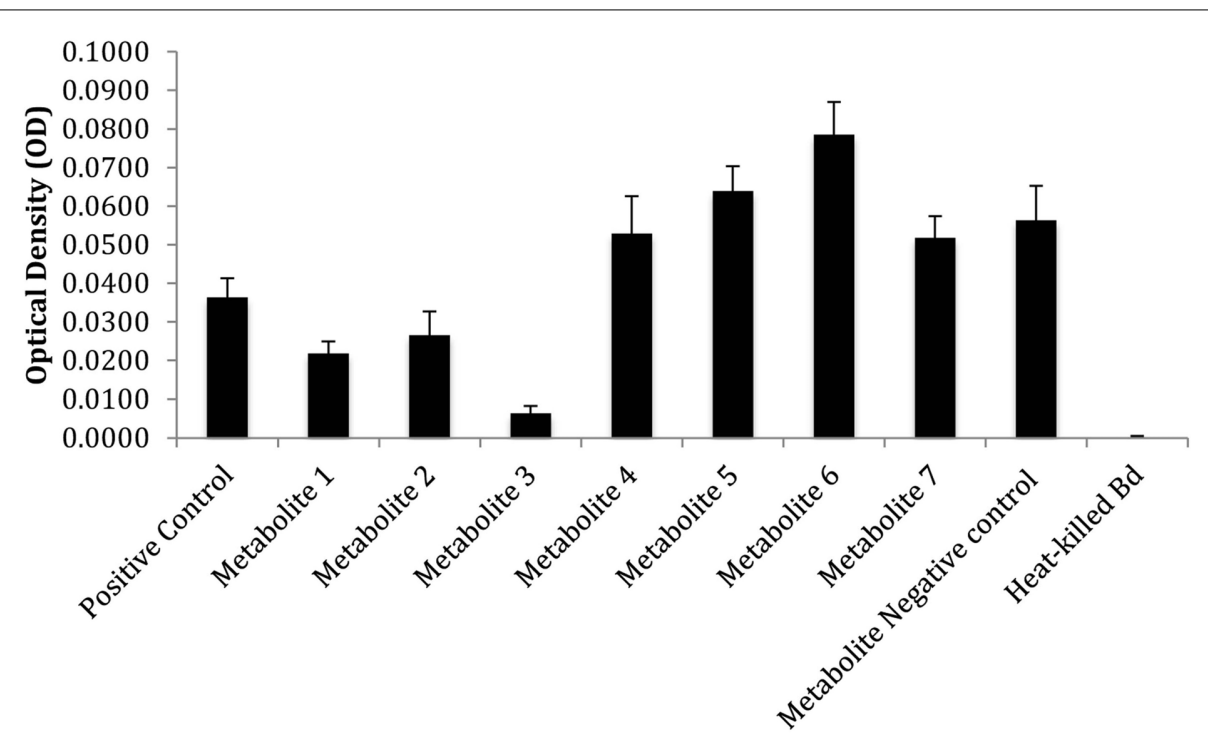

FIGURE 4 | Inhibitory properties of emergent metabolite fractions 1-7 at low unquantifiable concentrations. An additional control, "metabolite negative control," was also included, which was a fraction that contained no metabolites. The bars reflect standard deviation.

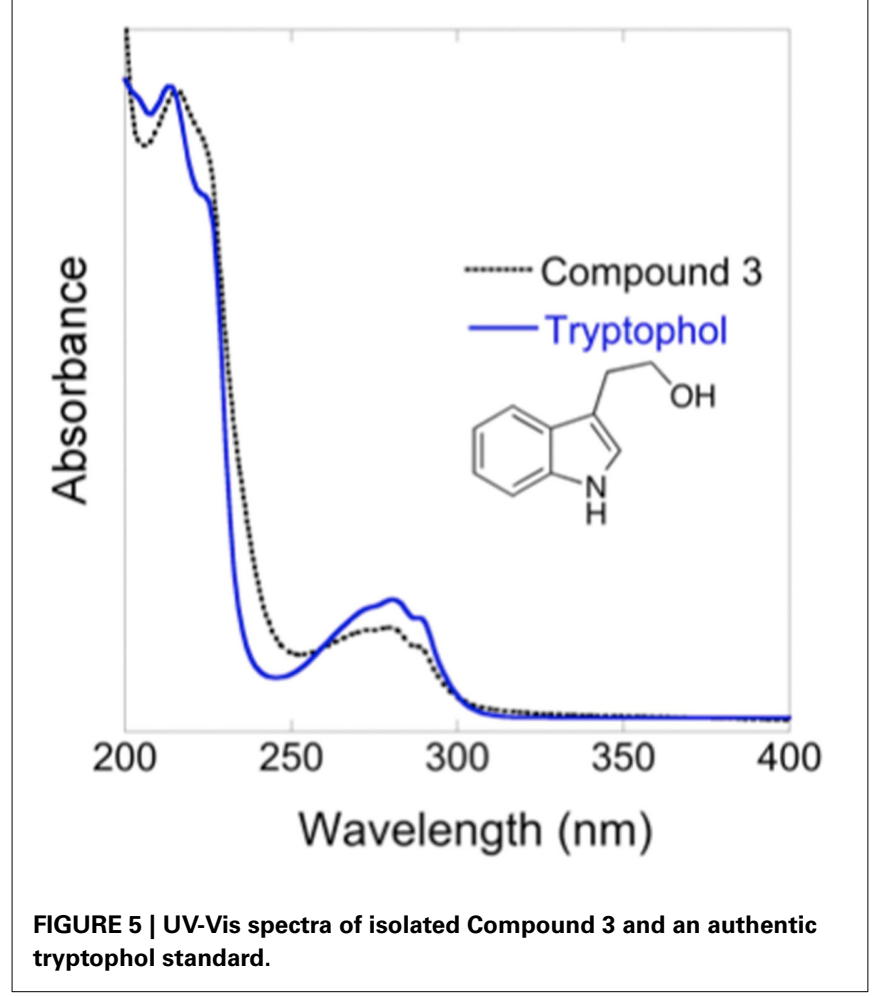

competition. Results from theory suggest that beneficial, antibiotic-producing bacteria are favored over bacteria that do not produce such compounds as long as the host supplies adequate resources for antibiotic production (Scheuring and Yu, 2012). Although we expect that competition has driven the production of emergent metabolites and an overall greater inhibitory function, competition was not measured, and it is

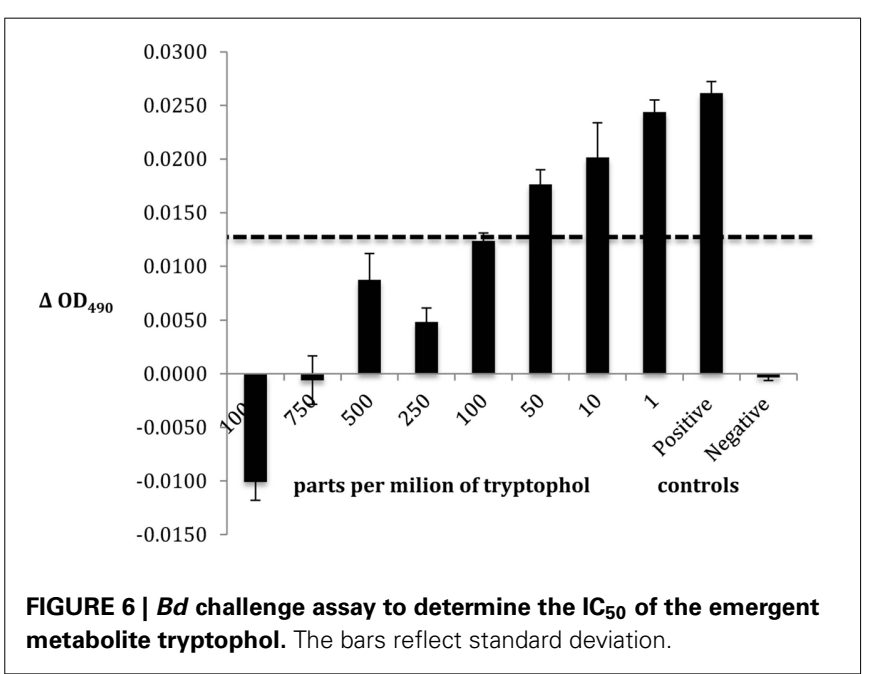

possible that other interactions, such as cooperation, led to our results.

This work reveals the complexity of microbial interactions and emphasizes the importance of considering such interactions when developing a bacterial probiotic as a conservation strategy. Furthermore, our results suggest that a bacterial probiotic with multiple bacterial species is more promising than a bacteria probiotic with a single bacterial species. Although a single trial to test bacterial probiotics with multiple bacterial species was unsuccessful on amphibians (Bletz et al., 2013), more work is needed to fully assess the potential of such therapy. Probiotic trials with a single isolate have been successful in some cases (Harris et al., 2009a,b), but not in others (Becker et al., 2011; Bletz et al., 2013). This variation could be explained by the probiotic interacting synergistically with the resident microbiota to inhibit $B d$ in the successful cases, but not synergistically inhibiting 
$B d$ or even facilitating $B d$ the unsuccessful cases. Bacterial probiotics with multiple bacterial species have been successful in mouse intestines (Lawley et al., 2012). In this study, the successful combination of bacteria used in the probiotic was selected by trial and error. This strategy was successful, however not efficient. It is likely important to choose bacteria that will compete interspecifically and produce more inhibitory metabolites. We propose choosing bacteria that display additive or synergistic relationships when in combination with other isolates over a range of concentrations and be highly inhibitory when co-cultured. If a bacterial isolate does not have an effect on $B d$ growth and does not produce any effect when combined with a second bacterial isolate, then it should be excluded from further consideration as part of a probiotic solution. To test whether the addition of multiple probiotics on amphibians worked in vivo, the defensive function of the mucosome could be measured, which would determine if the chemicals on an amphibian are anti-fungal prior to infection by a pathogen (Woodhams et al., 2014). Our results provide support for the use of a co-culture method in probiotic development that may lead to a more effective probiotic solution.

In conclusion, we found that metabolites produced by amphibians' skin bacteria in monoculture can be combined, and they can interact synergistically with each other to inhibit $B d$. In addition, we found that when these bacteria were co-cultured they were often even more inhibitory to $B d$, and they produced emergent metabolites that were not made by the bacteria when in monoculture. Furthermore, we identified the emergent metabolite tryptophol, which was the most active emergent metabolite against $B d$. These results will aid in developing combination of probiotics to mitigate the amphibian disease chytridiomycosis, in addition to contributing to our knowledge of bacterial and chemical interactions.

\section{ACKNOWLEDGMENTS}

We would like to thank NSF Grant \# 1136602 to Reid N. Harris and Kevin P. C. Minbiole for funding this project. In addition, we thank Dr. Eria Rebollar, Molly Bletz, Anthony Iannetta, and Celina Santiago for their assistance in the laboratory.

\section{SUPPLEMENTARY MATERIAL}

The Supplementary Material for this article can be found online at: http://www.frontiersin.org/journal/10.3389/fmicb.2014. 00441/abstract

\section{REFERENCES}

Becker, M. H., Brucker, R. M., Schwantes, C. R., Harris, R. N., and Minbiole, K. P. C. (2009). The bacterially produced metabolite violacein is associated with survival of amphibians infected with a lethal fungus. Appl. Environ. Microbiol. 75, 6635-6638. doi: 10.1128/AEM.01294-09

Becker, M. H., and Harris, R. N. (2010). Cutaneous bacteria of the redback salamander prevent morbidity associated with a lethal disease. PLoS ONE 5:e10957. doi: 10.1371/journal.pone.0010957

Becker, M. H., Harris, R. N., Minbiole, K. P., Schwantes, C. R., Rollins-Smith, L. A., Reinert, L. K., et al. (2011). Towards a better understanding of the use of probiotics for preventing chytridiomycosis in Panamanian golden frogs. Ecohealth 8, 501-506. doi: 10.1007/s10393-012-0743-0

Bell, S. C., Alford, R. A., Garland, S., Padilla, G., and Thomas, A. D. (2013). Screening bacterial metabolites for inhibitory effects against Batrachochytrium dendrobatidis using a spectrophotometric assay. Dis. Aquat. Org. 103, 77-85. doi: $10.3354 /$ dao02560
Bletz, M. C., Loudon, A. H., Becker, M. H., Bell, S. C., Woodhams, D. C., Minbiole, K. P. C. M., et al. (2013). Mitigating amphibian chytridiomycosis with bioaugmentation: characteristics of effective probiotics and strategies for their selection and use. Ecol. Lett. 16, 807-820. doi: 10.1111/ele.12099

Brucker, R. M., Baylor, C. M., Walters, R. L., Lauer, A., Harris, R. N., and Minbiole, K. P. C. (2008a). The identification of 2, 4-diacetylphloroglucinol as an antifungal metabolite produced by cutaneous bacteria of the salamander Plethodon cinereus. J. Chem. Ecol. 34, 39-43. doi: 10.1007/s10886-0079352-8

Brucker, R. M., Harris, R. N., Schwantes, C. R., Gallaher, T. N., Flaherty, D. C., Lam, B. A., et al. (2008b). Amphibian chemical defense: antifungal metabolites of the microsymbiont Janthinobacterium lividum on the salamander Plethodon cinereus. J. Chem. Ecol. 34, 1422-1429. doi: 10.1007/s10886-0089555-7

De Boer, W., Wagenaar, A. M., Klein Gunnewiek, P. J. A., and Van Veen, J. A. (2007). In vitro suppression of fungi caused by combinations of apparently non-antagonistic soil bacteria. FEMS Microbiol. Ecol. 59, 177-185. doi: 10.1111/j.1574-6941.2006.00197.x

Ghannoum, M. A., and Rice, L. B. (1999). Antifungal agents: mode of action, mechanisms of resistance, and correlation of these mechanisms with bacterial resistance. Clin. Microbiol. Rev. 12, 501-517.

Guzmán-López, O., Trigos, A., Fernández, F. J., de Jesús Yañez-Morales, M., and Saucedo-Castaneda, G. (2007). Tyrosol and tryptophol produced by Ceratocystis adiposa. World J. Microbiol. Biotechnol. 23, 1473-1477. doi: 10.1007/s11274-0079392-9

Harris, R. N., Brucker, R. M., Walke, J. B., Becker, M. H., Schwantes, C. R., Flaherty, D. C., et al. (2009b). Skin microbes on frogs prevent morbidity and mortality caused by a lethal skin fungus. ISME j. 3, 818-824. doi: 10.1038/ismej. 2009.27

Harris, R. N., James, T. Y., Lauer, A., Simon, M. A., and Patel, A. (2006). Amphibian pathogen Batrachochytrium dendrobatidis is inhibited by the cutaneous bacteria of amphibian species. Ecohealth 3, 53-56. doi: 10.1007/s10393-0050009-1

Harris, R. N., Lauer, A., Simon, M. A., Banning, J. L. M., and Alford, R. A. (2009a). Addition of antifungal skin bacteria to salamanders ameliorates the effects of chytridiomycosis. Dis. Aquat. Org. 83, 11-16. doi: 10.3354/dao02004

Hoffmann, M., Hilton-Taylor, C., Angulo, A., Böhm, M., Brooks, T. M., Butchart, S. H., et al. (2010). The impact of conservation on the status of the world's vertebrates. Science 330, 1503-1509. doi: 10.1126/science. 1194442

Kilpatrick, A. M., Briggs, C. J., and Daszak, P. (2010). The ecology and impact of chytridiomycosis: an emerging disease of amphibians. Trends Ecol. Evol. 25, 190-118. doi: 10.1016/j.tree.2009.07.011

Kueneman, J. G., Parfrey, L. W., Woodhams, D. C., Archer, H. M., Knight, R., and McKenzie, V. J. (2013). The amphibian skin-associated microbiome across species, space and life history stages. Mol. Ecol. 23, 1238-1250. doi: $10.1111 /$ mec. 12510

Lauer, A., Simon, M. A., Banning, J. L., Andre, E., Duncan, K., and Harris, R. N. (2007). Common cutaneous bacteria from the eastern red-backed salamander can inhibit pathogenic fungi. Copeia 3, 630-640. doi: 10.1643/00458511(2007)2007[630:CCBFTE]2.0.CO;2

Lawley, T. D., Clare, S., Walker, A. W., Stares, M. D., Connor, T. R., Raisen, C., et al. (2012). Targeted restoration of the intestinal microbiota with a simple, defined bacteriotherapy resolves relapsing Clostridium difficile disease in mice. PLoS Pathog. 8:e1002995. doi: 10.1371/journal.ppat.1002995

Lingappa, B. T., Prasad, M., Lingappa, Y., Hunt, D. F., and Biemann, K. (1969). Phenethyl alcohol and tryptophol: autoantibiotics produced by the fungus Candida albicans. Science 163, 192-194. doi: 10.1126/science.163. 3863.192

Loudon, A. H., Woodhams, D. C., Parfrey, L. W., Archer, H., Knight, R., McKenzie, V., et al. (2013). Microbial community dynamics and effect of environmental microbial reservoirs on red-backed salamanders (Plethodon cinereus). ISME J. 8, 830-840. doi: 10.1038/ismej.2013.200

McKenzie, V. J., Bowers, R. M., Fierer, N., Knight, R., and Lauber, C. L. (2011). Cohabiting amphibian species harbor unique skin bacterial communities in wild populations. ISME J. 6, 588-596. doi: 10.1038/ismej.2011.129

Myers, J. M., Ramsey, J. P., Blackman, A. L., Nichols, A. E., Minbiole, K. P. C., and Harris, R. N. (2012). Synergistic inhibition of the lethal fungal pathogen Batrachochytrium dendrobatidis: the combined effects of symbiotic bacteria 
metabolites and antimicrobial peptides of the frog Rana muscosa. J. Chem. Ecol. 8, 958-965. doi: 10.1007/s10886-012-0170-2

Rey, P., Leucart, S., Desilets, H., Bélanger, R. R., Larue, J. P., and Tirilly, Y. (2001). Production of indole-3-acetic acid and tryptophol by Pythium ultimum and Pythium group F: possible role in pathogenesis. Eur. J. Plant Pathol. 107, 895-904. doi: 10.1023/A:1013187922191

Rosazza, J. P., Juhl, R., and Davis, P. (1973). Tryptophol formation by Zygosaccharomyces priorianus. Appl. Microbiol. 26, 98-105.

Scheuring, I., and Yu, D. W. (2012). How to assemble a beneficial microbiome in three easy steps. Ecol. Lett. 11, 1300-1307. doi: 10.1111/j.14610248.2012.01853.x

Stuart, S. N., Chanson, J. S., Cox, N. A., Young, B. E., Rodrigues, A. S. L., Fischman, D. L., et al. (2004). Status and trends of amphibian declines and extinction worldwide. Science 306, 1783-1786. doi: 10.1126/science. 1103538

Sugawara, F., and Strobel, G. A. (1987). Tryptophola phytotoxin produced by Drechslera nodulosum. Phytochemistry 26, 1349-1351. doi: 10.1016/S00319422(00)81810-5

Umile, T. P., McLaughlin, P. J., Johnson, K. R., Honarvar, S., Blackman, A. L., Burzynski, E. A., et al. (2014). Nonlethal amphibian skin swabbing of cutaneous natural products for HPLC fingerprinting. Anal. Methods 6, 3277-3284. doi: 10.1039/c4ay00566j

Vredenburg, V. T., Briggs, C. J., and Harris, R. N. (2011). "Host-pathogen dynamics of amphibian chytridiomycosis: the role of the skin microbiome in health and disease," in Fungal Diseases: An Emerging Challenge to Human, Animal, and Plant Health, eds L. Olsen, E. Choffnes, D. A. Relman, and L. Pray (Washington, DC: The National Academies Press), 342-355.

Wake, D. B., and Vredenburg, V. T. (2008). Are we in the midst of the sixth mass extinction? A view from the world of amphibians. Proc. Nat. Acad. Sci. U.S.A. 105 (Suppl. 1), 11466-11473. doi: 10.1073/pnas.0801921105
Walke, J. B., Becker, M. H., Loftus, S. C., House, L. L., Cormier, G., Jensen, R. V., et al. (2014). Amphibian skin may select for rare environmental microbes. ISME J. doi: 10.1038/ismej.2014.77. [Epub ahead of print].

Woodhams, D. C., Brandt, H., Baumgartner, S., Kielgast, J., Küpfer, E., Tobler, U., et al. (2014). Interacting symbionts and immunity in the amphibian skin mucosome predict disease risk and probiotic effectiveness. PLoS ONE 9:e96375. doi: 10.1371/journal.pone.0096375

Woodhams, D. C., Vredenburg, V. T., Simon, M. A., Billheimer, D., Shakhtour, B., Shyr, Y., et al. (2007). Symbiotic bacteria contribute to innate immune defenses of the threatened mountain yellow-legged frog, Rana muscosa. Biol. Conserv. 138, 390-398. doi: 10.1016/j.biocon.2007.05.004

Conflict of Interest Statement: The authors declare that the research was conducted in the absence of any commercial or financial relationships that could be construed as a potential conflict of interest.

Received: 06 June 2014; accepted: 04 August 2014; published online: 21 August 2014. Citation: Loudon AH, Holland JA, Umile TP, Burzynski EA, Minbiole KPC and Harris $R N$ (2014) Interactions between amphibians' symbiotic bacteria cause the production of emergent anti-fungal metabolites. Front. Microbiol. 5:441. doi: 10.3389/fmicb. 2014.00441

This article was submitted to Microbial Symbioses, a section of the journal Frontiers in Microbiology.

Copyright (C) 2014 Loudon, Holland, Umile, Burzynski, Minbiole and Harris. This is an open-access article distributed under the terms of the Creative Commons Attribution License (CC BY). The use, distribution or reproduction in other forums is permitted, provided the original author(s) or licensor are credited and that the original publication in this journal is cited, in accordance with accepted academic practice. No use, distribution or reproduction is permitted which does not comply with these terms. 